\title{
Obstacles of Saudi Woman Work in the Mixed Environment: A Field Study
}

\author{
Mohammad Abdullah AL-Hazmi ${ }^{1}$, Mohammad Ahamd Hammad ${ }^{2}$ \& Hend Faye AL-Shahrani ${ }^{3}$ \\ ${ }^{1}$ Education \& Psychology department, Najran University, Saudi Arabia \\ ${ }^{2}$ Faculty of Education, Najran University, Saudi Arabia \\ ${ }^{3}$ Social Planning Department, Princess Nourah bint Abdulrahman University, Saudi Arabia \\ Correspondence: Mohammad Abdullah AL-Hazmi, Education \& Psychology Department, Najran University, \\ Saudi Arabia. E-mail: mohd400@hotmail.com
}

Received: August 22, 2016

doi:10.5539/ies.v10n8p128
Accepted: March 30, 2017 Online Published: July 29, 2017

URL: https://doi.org/10.5539/ies.v10n8p128

\begin{abstract}
The study aimed to identify the obstacles facing Saudi woman while working in a mixed work environment. The main study sample consisted of (223) from the health sector female affiliates and were divided into two groups. The first group consisted of (129) participants from the health sector and workers in Riyadh, Kingdom of Saudi Arabia (KSA) hospitals. The second group involved (94) participants from the health sector and workers in Najran, KSA hospitals. The study adopted the descriptive and analytical approach and the study instrument consisted of a questionnaire to identify the obstacles that the Saudi women encounter in the mixed environment. Results indicated that the most serious obstacles that Saudi woman encounters in the mixed work environment were social, professional, ethical, and psychological obstacles. There were statistically significant differences between the mean scores of women working in Riyadh and those women who working Najran regarding to the social obstacles in favor of women working in Najran and the ethical obstacles in favor of women working in Riyadh. There were no statistically significant differences between both groups in accordance to psychological and professional obstacles and the overall questionnaire degree. Furthermore, there were significant differences due to the nature of the work, whether a physician, nurse, or administrative employee regarding the social obstacles in favor of the woman working the administration field. There were significant differences with regard to both ethical and psychological obstacles in favor of women working in the administration field.
\end{abstract}

Keywords: work obstacles, mixed work environment, Saudi woman, psychological obstacles, ethical obstacles, professional obstacles, moral obstacles

\section{Introduction}

There is no doubt that Saudi women represent half of Saudi society, if not the majority. Saudi woman is the main man's partner as she is his mother, sister, daughter, wife and mate in the economic life in terms of her ability for production, development, and advancing progress and prosperity. There were some trends and methods of socialization that focus on the single woman's family role and do not recognize the multiplicity of her family and community roles, which in turn causes her to leave work and stop continuity and progress in the activities of public life, (Howaishah, 2010). Nevertheless, the view of Saudi society towards the Saudi woman is in general and particularly but without violating the woman's main functions towards her home, children and husband, (Al-Fawzan, 2012).

The issue of women's work is no longer the fundamental issue that should be on the table of dialogue. The appropriateness of work environment where the woman works has been the urgent and important issue. This environment could be either helpful for her to develop her character and contribute to nation's economic and social development or disabling one where many obstacles lie causing many psychological and social problems that not only affect her and her family but also the whole society.

The woman's work in mixed work environments might expose her to harassment or other forms of abuse and violence that cause her non-emotional stability, psychological combustion, and sense of hopelessness and anxiety. Consequently, she starts to leave work, be absent, or look for sick leaves, which on the long term affects family and community (Adib et al., 2002). 


\subsection{The Work of Saudi Woman}

There is no doubt that the woman's status in most of all over the world has improved a lot since 1950. The gap between the two genders in the field of education, for instance, has decreased a lot because of females' enrollment in the elementary schools, particularly in the Middle East, Southern and Eastern Asia, and North Africa. More women joined the workforce and accordingly the gap between both genders was somehow bridged in terms of wages and work opportunities (World Bank, 2001). Oufi (2003) emphasized the fact that woman's joining the workforce has been a social phenomenon after the industrial revolutions that humanity has witnessed. Proportions of working women have risen to be about one third of the working force in most advanced communities. Woman's going out to work field has also become a need dictated by the economic circumstances and conditions of social life. Women education has been acceptable among many people and common in our social lives. Work is defined as "every lasting and systematic human activity to achieve the goals and satisfy specific needs mostly economic and then psychological and political. Work is either a muscle or nervous activity or usually both the economic activity whether. In other words, it is the, whether physically or intellectually, in the economic activity for economic return (Ghaith 2005, p. 142). Work is also known as "any activity or effort done by the man or woman to serve the work owner and under his authority and supervision for a pay of any kind" (Al-Tarif, 2014, p. 20).

Saudi woman represent half of the Saudi society, if not more. She is the man's partner in the social life as she is his mother, sister, daughter, wife, and partner in the social and economic. She participates in the production, development and advancement of the community progress and prosperity (Ibrahim, 2013). In addition, woman while participating in the labor market is closely related to the state-oriented policies towards economic and human resources development through which Saudi society has undergone. Saudi woman began to join the labor market when Saudi Arabia reconsidered the causes of education in 1380. Accordingly, Saudi woman could participate in the labor market (Al-Yousef, 2005).

A look at the work systems in Saudi Arabia and the women's share of them can reveal that regulations of the Ministry of Civil Service do not differentiate between men and women in all matters related to employment, vacations or salaries. Work systems gave the woman special conditions in terms of motherhood and full-time for the newborn. They granted her work breaks with half or quarter salary payment for three years (Al-Shamlan, 2008).

Despite the increased attention in woman's issues that the Saudi society has been witnessing and in her level of education, the reality of her participation in the labor market is still small as some Saudi women still suffer from poverty and the widespread of unemployment. The unemployment rate among female citizens in Saudi Arabia was in 2007 about (26.6\%), then it rose in 2008 to reach (26.9\%), and continued to rise in 2009 to reach (28.4\%), which is four times the rate of youth unemployment that was (6.9\%) in 2009 (Al-Tarif, 2014). Perhaps this is because most of the attitudes and methods of socialization focus on the woman's single role inside family, and do not recognize the multiplicity of her family and community roles, which is reflected negatively on women, whether psychologically or socially causing her to leave for work (Howaishah, 2010). Traditions, which reject woman's work, the high birth rate, the low employment opportunities and illiteracy, are of the main reasons for the shrink of woman's role in the labor markets. The objection of a large proportion of men to women's work, as well as their refusal to do homework, for disparaging reasons, are other sources of unemployment among women (Al-Ashqar 2013).

\subsection{Obstacles of Saudi Woman Work in the Mixed Environment}

The work environment is merely social situations involving multiple social interactions that may lead to feelings of fear, failure, pressure of competition, intense competition, fear of negative evaluation and quarrels with colleagues. An individual might respond to the above circumstances or feelings with great concern and constant tension, which helps depression and impairments in mental health (Argyle, 1993).

Gerges (2005, p. 360) defines the obstacle as: "a barrier whether concrete, moral, psychological or social, isolating man from his/her ambition and needs." in this study obstacles are "the challenges or difficulties facing the working women in the environment where she works inhibiting her from fulfilling her needs, achieving her ambitions, and participating effectively in the development of community development. In the meantime, work environment is "the work environment that involves both the man and woman inside the intuition or establishment without barriers separating them".

The working woman in the mixed environment usually faces increasing and heavy pressures while trying hard to perform all multiple and conflicting roles. Multiplicity of roles consequently lead to problems such as delays and absenteeism problems due to her child or husband illness, inappropriateness of work to her energy consumed at 
home, in addition to her relation with bosses, colleagues, and employees that affect her family (Najbah, 2014).

Although Saudi legislations included many items in favor of women, but they were, in reality, disabled and deactivated. That is, there are many obstacles or barriers that inhibit the contribution of Saudi woman in the labor market and limit her contribution as men partners to the efforts of development that our society needs today more than ever (Al-Tarif, 2014). Saudi woman faces obstacles that limit the most participants in the field of education. The most important obstacles facing Saudi woman are:

\subsubsection{Social Obstacles}

Traditional roles of man and woman played an important role in the weakness of woman's participation in the labor market and her subordination to the man. Her role was more limited to and concentrated on the household chores and giving birth reducing her chances of entering the labor market. The proportion of women's participation, even in the developed countries, is less than (25\%) in comparison with men. The woman, in the new industrial area in East Asia, also suffers from the weakness in her social rights by (40\%) compared with man (Kabeer, 2003; Faisal, 2011).

Woman's going out to work has resulted in many changes in the structure and function of the modern family. The most important manifestations of such change is the fact that the woman has been carrying out mixed roles. She has been under the pressure of her natural role and the society's values and beliefs towards her maternal role, on one hand and her obligations and commitments in the field of her work with all pressures and duties, on the other hand. Marital and family relations of the working woman may be affected as a result (Nadia, 2012).

Al-Tarif (2014) that was carried out on (600) non-working women whose mean age was about (30) years concluded that Saudi customs, traditions and culture were not convinced by the woman's enrolment in the works or jobs done by men. Most families do not allow woman to work in the mixed environment because of the negative view to such work that might reduce her chances to get married.

Al-Shammari (2007) and Abdullah (2008) confirm that there are many obstacles facing the woman to join the mixed work environment such as including. Customs, traditions and norms that are still embedded in the minds of some people may lead to fear, suspicion and skepticism of women enrolment in the common job.

Abdullah (2008) claims that the man usually imposes his tutelage on the woman when she joins the work in the mixed work environment even if she is of a higher rank, more competent, or more experienced than he is. In addition, the man, in the mixed work environment, has privileges from which the woman is deprived even though she deserves them due to the cultural legacies resulting from socialization.

Some of the obstacles that face Saudi woman when joining mixed work environment might be referred to a set of factors. The culture of society has a significant effect on the individuals' culture because of the dominance of male culture in the eastern countries such as Saudi Arabia and other Arab countries. The woman in these cultures believes that the man's power and authority is natural and acceptable, (Al-Saleh, 2011).

\subsubsection{Professional Obstacles}

Discrimination in the labor market exists between genders all over the world. Rates of males' participation in the workforce are higher than females. In the north of Asia, for example in (2006), it is found that there are only (42) working for every (100) working men, (Faisal, 2011).

Work environment is seen as a psychological and social atmosphere that arises from the interaction of individuals of human gathering for the sake of continuity and specific aim. Nevertheless, this group is governed by a set of rules, policies, and systems to achieve in advance these aims. There is a positive correlation between the work environment and workers' psychological health. The individuals' ability to face anxiety, stress and pressure- generating situations because of professional problems and conflicts and interaction troubles with colleagues or employers is much better as long as his/her duties and rights are clearer and his/her relations with colleagues are good (Al-Ja' afreh \& Helmi, 2005).

Many obstacles are generated in the mixed work environment such as, discrimination against women, which hinders her professional progress and gain of some positions. Discrimination in the mixed work environment has two forms, formal and informal. Formal discrimination is seen when resources and positions are distributed inside the establishment unfairly. Informal discrimination takes place in the level of relationships established among individual of that establishment. Discrimination creates a work environment, which negatively affects the woman more than the man and consequently her loyalty to the establishment decreases (Al-Nabi, 2013).

Discrimination between man and woman is also found evident in the mixed work environment where the man has a lot of rewards, higher salaries and benefits compared with the woman of the same qualifications and years 
of experience, in women with men (Faisal, 2011). Statistics of World Bank Report indicate that the payment rate of the working women in the industrial countries equals about (77\%) of the men's payment rate, while it in the developing equals (73\%) (World Bank Report, 2011). International Labor Organization (ILO) talks about another type of discrimination in the mixed work environment known as "professional discrimination" which is associated with the society's cultural and social aspects that vary from one society to another (ILO, 2004). Faisal (2011) divides this type of discrimination into two parts, horizontal and vertical professional discrimination. The first part refers to the heavy presence of women in jobs that are of low-promotion and payment level. The second type refers to the heavy presence of men in senior positions at the institution's organizational pyramid.

Wei-Hsin (2005) points to the so-called occupational discrimination that exists in varied proportions in most countries all over the world. Among the developed countries involved in the study is the USA where the woman obtained (46\%) of the senior administrative because women there are more successful in claiming their rights. The lowest proportion (9\%) because the cultural environment obliges the woman to be always obedient for the man.

Faisal (2011) mentions that professional discrimination in some Islamic countries is higher. Pakistan, Bangladesh and Saudi Arabia accounted for $(8 \%, 7 \%$ and 1\%), respectively, regarding women's senior administrative positions in comparison with men. Malaysia was an exception in the Islamic countries group where women got $(21 \%)$ of the senior administrative positions.

Mitra (2003) believes that there is a gap between the wages of men and women despite the fact that some women present got senior administrative jobs in big institutions. Men usually are paid more than women for the same job level.

Connell (2006) argues that woman's work in the mixed institutions may have some bias on the part of managers who tend to work with males and assign them a number of tasks. The stability of male's superiority idea in managers' minds despite the woman's competencies and capabilities enhance this bias.

Human resources managers in the mixed work environment face many restrictions in creating opportunities of equality between men and women such as:

- the difficulty to appoint women in decision-making positions because of the lack of suitable candidates for these job,

- the many problems in the elimination of gender-based discrimination regarding the appointments, promotions, payment and disciplinary procedures issues,

- the difficulty to convince managers and decision makers in the mixed work environment to allow their female employees to get training opportunities equal to male ones, and

- the challenges in monitoring and reporting on some sensitive issues in the mixed work environment, such as sexual harassment in the workplace (Commonwealth Secretariat, 1999).

\subsubsection{Moral Obstacles}

Many countries did their best to open up many work areas for the women and consequently she achieved a lot and succeeded at all levels. Nevertheless, she is facing many psychological, physical and social problems and pressures resulting from conflicts at work environment, which may reach the sexual harassment attempts by work colleagues (Al-Shehri \& Al-Hindi, 2015).

Despite the fact that Saudi society is realistic and gradually accepts woman's work, it quickly evokes the risks regarding pushing her in all business fields. Therefore, the outlook, which is stemmed from Sharee'a and which is rooted in the hearts of the community, remains the main criterion for the idea of accepting or rejecting the idea of woman's work (Al-Zahrani, 2011).

The woman, in the mixed work environment, is exposed to some harassment by some co-workers of vulnerable souls and morals. This harassment is represented in verbal statements or immoral behaviors that are against sensible values and ethics.

Harassment problem, from which the woman in the mixed work environment suffers a lot, has received an intensive interest by scientists and researchers. It has been an accelerating phenomenon that worries all societies because of the high numbers of working women and the much time they spend interacting with their male colleagues in the mixed work environment (Al-Shehri \& Al-Hindi, 2015).

Many studies have discussed the problem of woman harassment in the mixed work environment. Reuters Global Agency in (2010) conducted a poll on (24) countries. Results showed that Saudi Arabia was in the third rank in 
accordance to sexual harassment. The poll also revealed that $(16 \%)$ of Saudi working women might have harassed sexually in the mixed work environment by their co-workers. This percentage is relatively high in comparison with other advanced countries whose harassment rates did not exceed (4\%), (Reuters, 2010).

\subsubsection{Ethical Obstacles}

Chaudhuri (2006) pointed out that the working woman in health sector at Calcutta city in India preferred silence in opposite of harassment in the mixed work environment. They feared to be blamed or to lose their good reputation inside a community completely dominated by masculine culture. Al-Shehri and Al-Hindi (2015) that was carried out on (206) employees in Saudi banking sector found out that (88.8\%) of participants agreed on the fact that woman's silence in opposite the sexual harassment, which may be due to the spread of the masculine culture in the society and the fear of its effects on her reputation and the reputation of her family, too. The absence of harassment deterrent laws and regulations were of the main reasons that make woman a target for harassers.

Findings of Khader (2011) were in agreement with the results of previous studies regarding the obstacles facing the woman in the mixed work environment such as health sector. Male staff at the hospital, where they were working, especially in the night shift, harassed female employees. The reasons for the low perception toward female employees in health profession are because such work does not conform to the prevailing values in Saudi society.

\subsubsection{Psychological Obstacles}

Ibrahim (2013) argued that the woman's going out to work created an overlapping, opposition, and conflict in her roles, which caused a kind of psychological pressure on her. The woman was, in many times, found in front of various requirements and expectations and difficult or sometimes impossible alternatives. Her home requirements might not enable her to perform perfectly her husband's expectations. Her children demands; home demands; and lack of time, effort and force might affect her home requirements, too and cause a big impact on her psychological aspects.

Sepahi (1997) pointed out to the psychological problems that the working mother often suffers from. Such problems are related to her children's custody child and family burthens. Results also showed that there is a negative impact on her production in terms of quantity and quality associated with the nursery problems and family burdens.

Sa'ad (2012) claims that there are many obstacles that woman may face in the mixed work environment amongst the most important of is violence against her, whether explicit and physical or implicit including verbal, emotional expressions or abnormal gestures.

\subsection{Statement of the Problem}

The contribution of Saudi woman in the labor market does not exceed (5\%) of the workforce in Saudi Arabia. The majority of jobs that she has joined are confined to the field of education, where he $(84 \%)$ of the total feminine jobs in the government sector, in addition to (4\%) in the field of health services resulting in a decrease in the contribution of Saudi woman in the labor market, (Al-Youssef, 2005).

Social and economic circumstances have led to an increase in the demand for jobs by Saudi women. Many of the development plans focused on developing the situations of woman and empowering her to participate in the economic and social development and to think of an adjustment in the work environment that commensurate, the legitimate women's work controls (Abdullah, 2012).

A study carried out by Mrs. Khadija Bent Khuwaylid Center in (2013) found out that there were many unethical infringements in the mixed work environment. About (88\%) of the study population pointed out that the adoption of the infringements law will have a positive impact on the woman's sense of safety, psychological comfort and parents' reassurance, which will be reflected in her increased participation in the labor market.

Several studies have indicated that (11-40\%) of working women in elderly care organizations are subjected to violence in the workplace. Nurses in their workplaces subjected to many forms of violence, whether physical, verbal or emotional, (Astrom et al., 2002; Viitasara et al., 2003). There are also other obstacles in the mixed work environment such discrimination between men and women regarding promotions, training, salaries, benefits and allowances, and health insurance provided by the employer (Khadija Bent Khuwaylid Center, 2013).

Ratios of violence forms against women in the mixed work environments are well known and documented in the Western societies whereas they are not so in the Arab societies. Only serious accidents and problems are reported 
and documented. The nature of the relationship between both the victim and the aggressor may play a major role in not documenting these violence actions where the victim knows well the aggressor. It is also believed as a waste of time because of the managers' low support. Sometimes, reporting such incidents is not effective and does not make a difference, while in some cases, they are believed as an integral part of the nature of the work (Sharipova et al., 2008).

Al-Fawzan (2012) believes that in spite of the importance of the woman's role from a social and economic point of view, she must work in the appropriate fields that fit her composition and nature as a female. Her going out for work must be through the Islamic Sharia, which limits some of the problems facing the Saudi women in the labor institutions. Al-Tarif (2014) confirmed this fact and pointed out that to empower the woman for real contribution in the process of the society's progress and prosperity, to provide the best of her capabilities and expertise, and to highlight her ability and skill, the working environment in which she work must be improved. The problems or obstacles that she is exposed to should be identified in order to raise her awareness, to benefit from her powers and involve her in the decision-making process of development. Procedures for wiping out all obstacles that limit her participation in the labor market should be developed.

Therefore, the present study aims to identify the obstacles facing the Saudi woman in the mixed work environment. The following main question can sum up the problem, "what are the obstacles that face the Saudi woman in the mixed work environment?. The following sub-questions will be answered, too.

1) What are the most influential obstacles on the Saudi woman in the mixed work environment?

2) Do the obstacles facing the Saudi woman in the mixed work environment vary according to the place of residence whether Najran or Riyadh?

3) Do the obstacles facing the Saudi woman in the mixed work environment vary according to the nature of work whether a physician, nurse, or manager?

4) What is the perceived proposal, which can be applied to reduce these barriers and their negative effects on Saudi women working in the mixed work environment?

\section{Method}

\subsection{Study Method}

The present study aimed to identify the obstacles that face the Saudi woman in the mixed work environment. The descriptive analytical approach for data collection and analysis was used. Results can be translated into some recommendations that can contribute to the reduction of obstacles and their negative effects faced by Saudi women in the mixed work environment.

\subsubsection{Study Sample}

The study sample consisted of (223) participants of the health sector female affiliates. They were divided into two groups. The first group involved (129) participants from the health sector female affiliates and workers at hospitals in Riyadh. The second group consisted of (94) participants from the health sector female affiliates and workers at hospitals in Najran, KSA.

\subsection{Study Instrument}

The main instrument for data gathering in the present study used was a questionnaire for the obstacles of Saudi woman's work in the mixed environment as. It consisted of three fields. The first field involved information about each participant such as name, place of work, nature of work ...etc. The second field involved (41) items distributed to four dimensions. The first dimension was the social obstacles and involved (10) items. The second dimension constituted the ethical obstacles and had (12) items. The third and fourth dimensions involved the psychological and professional obstacles and involved (8) and (11) items respectively. The third field in the study instrument was of two parts. The first one presented a set of solutions and suggestions as perceived by the researchers' point of view to meet the obstacles of the Saudi woman' work in the mixed work environment. The second part presented an open question that required participants to to write down their views and suggestions for facing the Saudi woman's obstacles in the mixed work environment.

Answering the items of this questionnaire was done via a graded scale of five alternatives (strongly agree, agree, agree to some extent, disagree, strongly disagree). Each respondent had to read carefully each item and select one response. The degree on each item was ranging from one to five, and thus the highest score obtained by each respondent was (260) degrees, and the lowest was (52). 


\subsubsection{Validity of the Questionnaire}

Arbitrators' validity

The questionnaire was presented to a group of specialists in education, psychology and mental health. Then in the light of their views, some items were modified and drafted. Validity of internal consistency was calculated using Pearson correlation coefficient of two levels. The first level was calculated according to the degree of correlation of each paragraph with the total degree of the questionnaire. Results showed that all correlation coefficients between the scores of each item regarding the obstacles of Saudi woman's work in the mixed environment and the total score of the questionnaire are significant $(\alpha=0.01)$ and $(\alpha=0.05)$. The internal consistency of the questionnaire was extracted through the degree of each dimension and the total score of the questionnaire. Table (1) illustrates these correlation coefficients.

Table 1. Correlation coefficients between the degree of each dimension and the total degree of the questionnaire $(\mathrm{N}=50)$

\begin{tabular}{lll}
\hline N. & Dimensions & Correlation coefficients \\
\hline 1 & Social obstacles & $0.59^{* *}$ \\
2 & Ethical obstacles & $0.80^{* *}$ \\
3 & Psychological obstacles & $0.81^{* *}$ \\
4 & Professional obstacles & $0.72^{* *}$ \\
\hline
\end{tabular}

** Significant $(\alpha=0.01)$.

Table 1 reveals that the correlation coefficients between the questionnaire dimensions and the total score are significant at $(\alpha=0.01)$, which proves that the questionnaire is characterized by a high degree of validity.

\subsubsection{Reliability of the Questionnaire}

Reliability of the study instrument (questionnaire) was calculated using these ways. Cronbach Alpha was used to find out the reliability of each dimension and its total degree. Reliability coefficients were $(0.74,0.75,0.81$, and 0.79 ) for the first, second, third and fourth dimension respectively. The total degree was (0.84). All these coefficients were having high reliability rates indicating that the questionnaire was reliable. Test and retest method was also used for calculating the reliability of the questionnaire after being applied to the exploratory sample. Two weeks later, it was repeated and applied to the same sample. Pearson correlation is between participants' scores in the first and second applications of the questionnaire's dimensions questionnaire and the total score. Reliability coefficients for the questionnaire's dimensions were $(0.72,0.74,0.79$, and 0.81$)$ for the first, second, third, and fourth dimension respectively. The total degree was (0.82). All these coefficients were of high reliability rates indicating a high reliability degree of the questionnaire's dimensions on one hand, and the questionnaire as a whole, on the other hand.

\section{Results}

\subsection{Results Related to the First Question}

To answer the first question that stated "What are the most influential obstacles on the Saudi woman in the mixed work environment?" mean scores and proportions of all items in the questionnaire were extracted. In addition, weighted means were also calculated for every dimension of the questionnaires dimensions as it was. The premise legal mean (3) was adopted as the maximum degree of the item was (5). If observed means of obstacles exceeded (3), they are to be seen as severe, while if they are below (3), they are not to be considered so. The following tables illustrate the results. 


\subsubsection{Results Related to the First Domain "Social Obstacles"}

Table 2. Means, standard deviations and proportions for all items in the social obstacles domain

\begin{tabular}{|c|c|c|c|c|}
\hline \multicolumn{5}{|c|}{ First domain: social obstacles facing Saudi woman in the mixed environment } \\
\hline N. & Items & $\mathrm{M}$ & $\mathrm{SD}$ & $\%$ \\
\hline 1 & Family reservation regarding my going out for work. & 3.93 & 0.92 & 78.62 \\
\hline 2 & Work at mixed environment might postpone my marriage. & 3.40 & 1.32 & 68.12 \\
\hline 3 & My husband objects my work in the mixed environment because of admixture. & 3.90 & 0.94 & 78.00 \\
\hline 4 & Night shifts cause many problems for me with my family. & 4.16 & 1.02 & 83.36 \\
\hline 5 & Rumors take place because of my work in a mixed environment with the man. & 3.49 & 1.19 & 69.86 \\
\hline 6 & My husband feels upset because of my going out at night in case of the night shifts, as the place is full of males. & 3.99 & 1.09 & 79.86 \\
\hline 7 & My parents refuse work in a mixed environment because of admixture. & 3.54 & 1.12 & 70.86 \\
\hline 8 & My husband practice pressure on me from time to time to leave wok because of admixture with the men. & 3.50 & 1.16 & 70.00 \\
\hline 9 & Work in a mixed environment does not fit dominant values in Saudi society. & 3.49 & 1.23 & 69.86 \\
\hline 10 & My husband feels angry when talking on telephone to a colleague about emergent work affairs. & 3.55 & 1.20 & 71.12 \\
\hline
\end{tabular}

Table 2 shows that means of the social obstacles facing the Saudi woman in a mixed work environment range between high $(\mathrm{M}=4.16)$ with a proportion about $(83.36 \%)$ and low $(\mathrm{M}=3.40)$ with a proportion about $(68.12 \%)$.

\subsubsection{Results Related to the Second Domain "Ethical Obstacles"}

Table 3. Means, standard deviations and proportions for all items in the ethical obstacles domain

\begin{tabular}{|c|c|c|c|c|}
\hline \multicolumn{5}{|c|}{ Second domain: Ethical obstacles facing Saudi woman in the mixed environment } \\
\hline N. & Items & $\mathrm{M}$ & $\mathrm{SD}$ & $\%$ \\
\hline 1 & The conservative view of the society towards the woman working in the mixed work environment. & 3.49 & 1.15 & 69.80 \\
\hline 2 & Comments of male colleagues on my appearance. & 3.00 & 1.11 & 60.00 \\
\hline 3 & Communication on the part of my male colleagues in the working hours for no real need. & 2.85 & 1.22 & 57.00 \\
\hline 4 & Some male colleagues transfer work discussions to topics outside the scope of work. & 3.23 & 1.09 & 64.60 \\
\hline 5 & Some people harass me at the mixed work environment. & 2.70 & 1.20 & 54.00 \\
\hline 6 & Some colleagues stare at me. & 3.00 & 1.19 & 60.00 \\
\hline 7 & Some colleagues make shameless noises or facial expressions. & 3.00 & 1.28 & 60.00 \\
\hline 8 & Some colleagues ask for meeting me outside work time. & 2.91 & 1.27 & 58.20 \\
\hline 9 & Some colleagues approach me more than needed during work time. & 2.75 & 1.30 & 55.00 \\
\hline 10 & The administration condone when filing a complaint against a colleague for harassing me at work. & 3.13 & 1.32 & 62.60 \\
\hline 11 & The absence of deterrent legislation and laws against colleagues who are morally transgressors. & 3.24 & 1.38 & 64.80 \\
\hline 12 & $\begin{array}{l}\text { There are some common practices in the work environment that conflict with the religious beliefs such as } \\
\text { mixing, ...etc. }\end{array}$ & 3.16 & 141 & 63.20 \\
\hline
\end{tabular}

Table 3 shows that means of the ethical obstacles facing the Saudi woman in a mixed work environment range between high $(\mathrm{M}=3.49)$ with a proportion about $(79.80 \%)$ and low $(\mathrm{M}=2.70)$ with a proportion about $(54.00 \%)$. 


\subsubsection{Results Related to the Third Domain "Psychological Obstacles"}

Table 4. Means, standard deviations and proportions for all items in the psychological obstacles domain

\begin{tabular}{|c|c|c|c|c|}
\hline \multicolumn{5}{|c|}{ Third domain: Psychological obstacles facing Saudi woman in the mixed environment } \\
\hline N. & Items & $\mathrm{M}$ & SD & $\%$ \\
\hline 1 & Lack of confidence of others whether my male or female colleagues. & 3.06 & 1.06 & 61.20 \\
\hline 2 & I feel the psychological pressure on the part of my family because of my work in a mixed environment with men. & 2.91 & 1.24 & 58.20 \\
\hline 3 & $\begin{array}{l}\text { I fear of and hate going to work because of what I am subjected such as harassment by male colleagues or } \\
\text { customers. }\end{array}$ & 2.83 & 1.10 & 56.60 \\
\hline 4 & My work in a mixed environment affects my harmony and agreement with my husband. & 2.91 & 1.14 & 58.20 \\
\hline 5 & $\begin{array}{l}\text { The low level of tranquility and psychological and social stability within my family because of my work in a } \\
\text { mixed environment and admixture with men. }\end{array}$ & 2.78 & 1.17 & 56.60 \\
\hline 6 & $\begin{array}{l}\text { I feel the tension and anxiety because of carrying a burden that may outweigh my energy and abilities in a mixed } \\
\text { work environment whether of my colleagues or clients. }\end{array}$ & 2.91 & 1.18 & 58.20 \\
\hline 7 & My psychological pressures are negatively reflected on my husband and children. & 3.03 & 1.12 & 60.60 \\
\hline 8 & I do not feel psychological safety during my stay in mixed work environment. & 3.03 & 1.20 & 60.60 \\
\hline
\end{tabular}

Table 4 shows that means of the psychological obstacles facing the Saudi woman in a mixed work environment range between high $(\mathrm{M}=3.06)$ with a proportion about $(61.20 \%)$ and low $(\mathrm{M}=2.78)$ with a proportion about $(55.60 \%)$.

\subsubsection{Results Related to the Fourth Domain "Professional Obstacles"}

Table 5. Means, standard deviations and proportions for all items in the professional obstacles domain

\begin{tabular}{|c|c|c|c|c|}
\hline \multicolumn{5}{|c|}{ Third domain: Psychological obstacles facing Saudi woman in the mixed environment } \\
\hline N. & Items & $\mathrm{M}$ & $\mathrm{SD}$ & $\%$ \\
\hline 1 & Senior management positions are limited to males. & 3.24 & 1.14 & 64.80 \\
\hline 2 & Some male bosses are authoritarian. & 3.59 & 1.17 & 71.80 \\
\hline 3 & The weakness of the professional achievement of both genders in the mixed work environment. & 3.07 & 1.10 & 61.40 \\
\hline 4 & The novelty of the medical specialties for women in Saudi universities. & 3.25 & 1.08 & 65.00 \\
\hline 5 & The long working hours in most mixed work environments, such as the health sector. & 3.64 & 1.09 & 72.80 \\
\hline 6 & The look of inferiority that some patients have toward me in the mixed work environment. & 3.38 & 1.11 & 67.60 \\
\hline 7 & The weakness of some male colleagues' confidence in my job abilities. & 3.20 & 1.05 & 64.00 \\
\hline 8 & Discrimination in job promotions between males and females in favor of males. & 3.21 & 1.06 & 64.20 \\
\hline 9 & Assigning some of the tasks that I can accomplish to males. & 3.24 & 1.05 & 64.80 \\
\hline 10 & Scarcity of engaging females by bosses in decision-making process related to work. & 3.37 & 1.05 & 67.40 \\
\hline 11 & The domination of males on the training and leadership programs. & 3.58 & 1.11 & 71.60 \\
\hline
\end{tabular}

Table 5 shows that means of the psychological obstacles facing the Saudi woman in a mixed work environment range between high $(\mathrm{M}=3.66)$ with a proportion about $(72.80 \%)$ and low $(\mathrm{M}=3.20)$ with a proportion about $(64.00 \%)$.

\subsubsection{Results of the Questionnaire as a Whole Are Shown in the Following Tables}

Table 6. Mean scores, standard deviations, and proportions of responses to each dimension

\begin{tabular}{lcccc}
\hline Dimensions & Items & M & SD & Weighted mean \\
\hline Social obstacles & 10 & 36.98 & 8.04 & 3.69 \\
Ethical obstacles & 12 & 36.46 & 11.11 & 3.03 \\
Psychological obstacles & 8 & 23.49 & 7.32 & 2.93 \\
Professional obstacles & 11 & 36.82 & 9.12 & 3.34 \\
The whole questionnaire & 41 & 133.75 & 29.07 & 3.26 \\
\hline
\end{tabular}

Table 6 shows the descending order of all dimensions according to their weighted means. It reveals that the social obstacles dimension occupied the first rank $(\mathrm{M}=3.69)$. In the second place was the professional obstacles 
dimension $(\mathrm{M}=3.34)$, the ethical obstacles dimension came in third place $(\mathrm{M}=3.03)$, and in the last rank was the psychological obstacles domain $(\mathrm{M}=2.93)$. The table also reveals that the weighted means of all dimensions in the questionnaire ranged from (2.93) to (3.69). That is, most means or scores are clearly more than the hypothesized mean (3.00) except the third dimension related to the psychological obstacles.

\subsection{Second: Results Related to the Second Question}

To answer the second question that stated "Do the obstacles facing the Saudi woman in the mixed work environment vary according to the place of residence whether Najran or Riyadh?" T. test for the significance of differences is between the means of scores of the working woman in Riyadh and the working woman in Najran on all dimensions of the questionnaire. Table 7 illustrates the results.

Table 7. Significance of the differences between the mean scores of the working women in Riyadh and Najran

\begin{tabular}{|c|c|c|c|c|c|c|}
\hline \multirow{2}{*}{$\begin{array}{l}\text { Obstacles of Saudi woman working in } \\
\text { a mixed environment }\end{array}$} & \multicolumn{2}{|c|}{$\begin{array}{l}\text { Women working in Riyadh } \\
(\mathrm{N}=129)\end{array}$} & \multicolumn{2}{|c|}{$\begin{array}{l}\text { Women working in Riyadh } \\
\qquad(\mathrm{N}=94)\end{array}$} & \multirow[t]{2}{*}{ T. ratio } & \multirow[t]{2}{*}{ Significance } \\
\hline & $\mathrm{M}$ & $\mathrm{SD}$ & $\mathrm{M}$ & $\mathrm{SD}$ & & \\
\hline Social obstacles & 36.47 & 8.27 & 38.92 & 6.72 & 2.36 & $\begin{array}{l}\text { Significant at } \\
\quad(\alpha=0.05)\end{array}$ \\
\hline Ethical obstacles & 36.74 & 10.73 & 32.44 & 11.22 & 2.89 & $\begin{array}{l}\text { Significant at } \\
\qquad(\alpha=0.01)\end{array}$ \\
\hline Psychological obstacles & 23.89 & 7.44 & 22.71 & 7.05 & 1.20 & Not significant \\
\hline Professional obstacles & 37.51 & 8.68 & 35.55 & 9.89 & 1.57 & Not significant \\
\hline Total score & 134.64 & 29.98 & 129.64 & 25.37 & 1.31 & Not significant \\
\hline
\end{tabular}

Table 7 shows that there were statistically significant differences $(\alpha=0.05) \&(\alpha=0.01)$ between the mean score of participant women working in Riyadh and the mean score of participant women working in Najran. Differences were in the dimension of social obstacles that were in favor of women working in Najran. Nevertheless, differences that were in the ethical obstacles were in favor of women working in Riyadh. The table also reveals that there are no statistically significant differences between the mean scores of both types of working women regarding the dimensions of psychological and professional obstacles, in addition to the total score of the whole questionnaire.

Results of the second question is seen logical where the traditions and customs of the tribal community are still having control on Najran in the southern part of Saudi Arabia. Furthermore, the social dimension is the dimension that worries the woman working in a mixed environment in Najran where many members within her community reject her admixture with men in the same place even though it is a public place. Unlike Najran, Riyadh is a civilized and open where the social obstacles, despite their importance for participants in the present study, do not represent the first obstacles dimension for the working woman. The ethical obstacles are really considered more important because of the harassment from the man's side due to the nature of somewhat open society.

With regard to the psychological and professional obstacles, there were no significant differences between the mean scores of both women in Najran and Riyadh. Problems of the same work and profession are somehow similar in all places, whether in Riyadh or Najran. Kanter (1997), for instance concluded that there were professional hindering the woman's professional and administrative progress in all jobs of the common nature despite the place of those jobs. Problems like the lack of equal opportunities with male counterparts and the lack of impact of the woman's experience and scientific qualification cause her to stay away from decision-making centers. Al-Subai'e (2010) and Al-Tarif (2014) claimed that there is much discrimination between men and women with regard to job promotions at mixed environments. The psychological problems that the working woman might face in the mixed environment are similar in all cities.

\subsection{Third: Results Related to the Third Question}

To answer the second question that stated "Do the obstacles facing the Saudi woman in the mixed work environment vary according to the nature of work whether a physician, nurse, or manager?" Mean scores and standard deviations of all participants' responses regarding the nature of the job. Table 8 illustrates the results. 
Table 8. Mean scores and standard deviations of participants' responses regarding the work nature

\begin{tabular}{lccccccc}
\hline \multirow{2}{*}{ Obstacles of Saudi woman working in a mixed environment } & \multicolumn{2}{c}{$\begin{array}{c}\text { Physician } \\
\text { N=44 }\end{array}$} & \multicolumn{2}{c}{$\begin{array}{c}\text { Nurse } \\
\text { N=81 }\end{array}$} & \multicolumn{2}{c}{ Manager } \\
\cline { 2 - 7 } & $\mathrm{M}$ & $\mathrm{SD}$ & $\mathrm{M}$ & $\mathrm{SD}$ & $\mathrm{M}$ & $\mathrm{SD}$ \\
\hline Social obstacles & 36.84 & 6.82 & 35.75 & 8.74 & 39.13 & 6.90 \\
Ethical obstacles & 32.48 & 10.17 & 33.16 & 11.82 & 37.25 & 10.53 \\
Psychological obstacles & 22.17 & 7.07 & 22.12 & 7.24 & 24.86 & 7.20 \\
Professional obstacles & 35.56 & 9,07 & 35.24 & 8.66 & 38.25 & 9.57 \\
\hline
\end{tabular}

To find out the significance of differences, One-Way Analysis of Variance (ANOVA) was used to calculate the differences between the participants' mean scores regarding the nature of work to identify on the dimensions of the obstacles of the Saudi woman working in a mixed environment. Table 9 illustrates the results.

Table 9. ANOVA results regarding work nature on all questionnaires' dimensions

\begin{tabular}{|c|c|c|c|c|c|c|}
\hline $\begin{array}{c}\text { Dimensions of } \\
\text { obstacles }\end{array}$ & Source of variance & Sum of squares & $\mathrm{DF}$ & $\begin{array}{l}\text { Mean of } \\
\text { squares }\end{array}$ & Calculated F. & Significance level \\
\hline \multirow{3}{*}{ Social } & Between groups & 539.50 & 2 & 269.75 & \multirow{3}{*}{4.65} & \multirow{3}{*}{ Significant $(\alpha=0.01)$} \\
\hline & Within groups & 12750.23 & 220 & 7505 & & \\
\hline & Total & 13289.74 & 222 & 15.95 & & \\
\hline \multirow{3}{*}{ Ethical } & Between groups & 1041.89 & 2 & 520.948 & \multirow{3}{*}{4.33} & \multirow{3}{*}{ Significant $(\alpha=0.01)$} \\
\hline & Within groups & 26438.09 & 220 & \multirow{2}{*}{120.17} & & \\
\hline & Total & 27479.99 & 222 & & & \\
\hline \multirow{3}{*}{ Psychological } & Between groups & 410.87 & 2 & 205.43 & \multirow{3}{*}{3.96} & \multirow{3}{*}{ Significant ( $\alpha=0.02)$} \\
\hline & Within groups & 11392.60 & 220 & \multirow{2}{*}{51.78} & & \\
\hline & Total & 11803.48 & 222 & & & \\
\hline \multirow{3}{*}{ Professional } & Between groups & 469.56 & 2 & 234.78 & \multirow{3}{*}{2.79} & \multirow{3}{*}{ Significant ( $\alpha=0.06)$} \\
\hline & Within groups & 18492.08 & 220 & \multirow{2}{*}{84.05} & & \\
\hline & Total & 18961.65 & 222 & & & \\
\hline \multirow{3}{*}{$\begin{array}{l}\text { The whole } \\
\text { questionnaire }\end{array}$} & Between groups & 93330.57 & 2 & 4665.28 & \multirow{3}{*}{6.14} & \multirow{3}{*}{ Significant ( $\alpha=0.03$ ) } \\
\hline & Within groups & 166978.98 & 220 & \multirow{2}{*}{758.99} & & \\
\hline & Total & 176309.56 & 222 & & & \\
\hline
\end{tabular}

Table 9 proves that there were statistically significant differences $(\alpha=0.01)$ and $(\alpha=0.05)$ in the social, ethical, and psychological dimensions due to the nature of work variable (physician, nurse, manager). Nevertheless, there were no significant differences in the professional dimension due to the variable of the nature of work. To identify the direction of these significant differences in the first three dimensions, Scheffe test was used for post comparisons as illustrated in Table 10 below.

Table 10. Results of Scheffe for differences' direction and significance o in the social, ethical and psychological obstacles dimensions due to the work nature

\begin{tabular}{|c|c|c|c|c|}
\hline Questionnaire dimensions & Participants & Physician & Nurse & Manager \\
\hline \multirow{3}{*}{ Social obstacles } & Physician & --- & --- & --- \\
\hline & Nurse & 1.09 & --- & --- \\
\hline & Manager & 2.28 & $3.38^{*}$ & --- \\
\hline \multirow{3}{*}{ Ethical obstacles } & Physician & --- & --- & --- \\
\hline & Nurse & 0.67 & --- & --- \\
\hline & Manager & -4.67 & $4.091^{* *}$ & --- \\
\hline \multirow{3}{*}{ Psychological obstacles } & Physician & --- & --- & --- \\
\hline & Nurse & 0.056 & --- & --- \\
\hline & Manager & -2.86 & $2.74 *$ & --- \\
\hline
\end{tabular}

*: significant at $((\alpha=0.05) ; *$ : significant at $(\alpha=0.01)$.

Table 10 shows that there were statistically significant differences due to the nature of work whether a physician, 
nurse, manager in the dimensions of social, ethical, and psychological obstacles. These differences were between the women working in the field of nursing and the women working in the field of administration in favor of women working in the administrative area.

\subsection{Fourth: Results Related to the Fourth Question}

To answer the fourth question that stated "What is the perceived proposal, which can be applied to reduce these barriers and their negative effects on Saudi women working in the mixed work environment? A set of proposals were put forward in the third part of the questionnaire related to how these work obstacles can be reduced at the mixed environment. Table 11 illustrates the participants' responses.

Table 11. Participants' responses to the proposals to reduce the obstacles of the Saudi woman at the mixed work environment

\begin{tabular}{|c|c|c|c|c|}
\hline \multicolumn{5}{|c|}{ Third part: proposals to reduce the work obstacles facing the Saudi woman in the mixed environment } \\
\hline N. & ems & $\mathrm{M}$ & $\mathrm{SD}$ & $\%$ \\
\hline & $\begin{array}{l}\text { rging the government and private institutions to separate men from women's side in the mixed work } \\
\text { lvironments. }\end{array}$ & 4.00 & 0.91 & 80.00 \\
\hline & $\begin{array}{l}\text { Rationing the conditions of the woman's work in the mixed work environment to ensure or to reduce her } \\
\text { mingling with man to the minimum. }\end{array}$ & 3.88 & 0.82 & 77.60 \\
\hline & $\begin{array}{l}\text { Using the modern means of communication when needed for meetings or discussing work-related issues without } \\
\text { the need for direct communication. }\end{array}$ & 4.01 & 1.01 & 80.20 \\
\hline & Demanding the enactment of legislation and laws that deter harassment and extortion towards women. & 4.37 & 0.84 & 87.40 \\
\hline & $\begin{array}{l}\text { Activating the participation of women working in the mixed environment in setting the policies, controls, } \\
\text { standards and procedures to enhance the sense of professional autonomy. }\end{array}$ & 4.25 & 0.71 & 85.00 \\
\hline & $\begin{array}{l}\text { Not allowing men to take over the training programs and set specialized programs for women working in the } \\
\text { mixed environment to develop her skills in the work field. }\end{array}$ & 4.43 & 0.76 & 88.60 \\
\hline & $\begin{array}{l}\text { Demanding for the woman's rights promotion, allowances and bonuses as well as the man in the mixed work } \\
\text { environment. }\end{array}$ & 4.44 & 0.72 & 88.80 \\
\hline & $\begin{array}{l}\text { Apply the instant penalties, such as dismissing, moving away, or salary deduction ... etc., when there is a } \\
\text { complaint of any type of harassment by any male colleague towards his female colleague. }\end{array}$ & 4.48 & 0.71 & 89.60 \\
\hline & Having perfect impartial systems in dealing with employees of both genders in the mixed work environment. & 4.19 & 0.82 & 83.80 \\
\hline & Managers, in the mixed work environment, should not discriminate between employees because of their gender. & 4.24 & 0.78 & 84.80 \\
\hline & Educating the women in the mixed work environment of her duties and rights through various media means. & 4.37 & 0.86 & 87.40 \\
\hline
\end{tabular}

Table 11 shows that the mean scores of the ways of overcoming the obstacles facing the Saudi women in the mixed work environment were ranging between high means (4.48) and low means (3.88). Proportions were $(89.60 \%)$ and $(77.60 \%)$ respectively. The highest mean score was for item (8) "Applying the instant penalties, such as dismissing, moving away, or salary deduction ... etc., when there is a complaint of any type of harassment by any male colleague towards his female colleague", $(M=4.48)$. Then item (7) "Demanding for the woman's rights promotion, allowances and bonuses as well as the man in the mixed work environment" $(\mathrm{M}=4.44)$. Item (6) "Not allowing men to take over the training programs and set specialized programs for women working in the mixed environment to develop her skills in the work field" $(\mathrm{M}=4.43)$ was in the third place. Items (4) "Demanding the enactment of legislation and laws that deter harassment and extortion towards women", (11) "Educating the women in the mixed work environment of her duties and rights through various media means", (5) "Activating the participation of women working in the mixed environment in setting the policies, controls, standards and procedures to enhance the sense of professional autonomy", and (10) "Managers, in the mixed work environment, should not discriminate between employees because of their gender" were in the fourth, fifth, sixth, and seventh ranks. Mean scores were (4.37), (4.37), (4.25), and (4.24) respectively. Items (9) "Having perfect impartial systems in dealing with employees of both genders in the mixed work environment", (3) "Using the modern means of communication when needed for meetings or discussing work-related issues without the need for direct communication", (1) "Urging the government and private institutions to separate men from women's side in the mixed work environments", and (2) "Rationing the conditions of the woman's work in the mixed work environment to ensure or to reduce her mingling with man to the minimum" were in the bottom of the list. Mean scores were (4.19), (4.01), (4.00), and (3.88) respectively. 


\section{Discussion}

\subsection{Discussion of the Results of the First Question}

Results of the first question have revealed that obstacles in the social, ethical and professional dimensions represent real and severe obstacles in front of Saudi woman when working in a mixed work environment. Obstacles in the psychological domain do not represent real obstacles for the Saudi woman. The general weighted mean of the whole questionnaire $(M=3.26)$ indicates the importance of paying attention to such obstacles that require enormous efforts to be overcome and solved.

The social obstacles $(\mathrm{M}=3.69)$, according to the results of the study, are of the most important obstacles facing the working woman in Saudi Arabia in comparison with other obstacles. That is, the social obstacles are of the most influential obstacles affecting the working woman in the mixed work environment. This can be because a large proportion of Saudi society rejects admixture of men and women in addition to her leaving for the night shifts. The item "Night shifts cause many problems for me with my family" and "My husband feels upset because of my going out at night in case of the night shifts as the place is full of males" got the highest proportions of participants' responses. Proportions were $(83.36 \%$ and $79.86 \%)$ respectively. This finding corroborates the result of Al-Jawhari (2000) and Al-Shammasi (2001), which indicated that some professions, like for instance health professions may lead to and cause admixture of women and men because of the regime of night shifts that are not in harmony with the dominant values in the Saudi society. Al-Zahrani (2011) mentioned that social obstacles might be more effective in the Saudi woman's work in a mixed work environment. This can be referred to the society's refusal for admixture and woman's dealing with man. The long hours spent by the woman at work play a significant role, too. The society has traditions among which the necessity of the woman's presence at home to care about her husband and children. The society refuses the woman's return at night because of the rumors and people's gossips about her work during the night shifts and her stay away from home. Thus, social obstacles were more effective in participants' responses because of their understanding of the culture of their society and sense that they are facing much criticism by their families and community members. In addition, some working women in the mixed work environment, particularly in the health domain are considered bad examples because of their conduct and dealing with men at workplace. Consequently, many of the parents and society refuse the woman's leaving for work in a mixed environment because of some women's bad behaviors which led to the society's look of inferiority towards them.

The ethical obstacles, as shown in Table 6 were in the second rank regarding the severity of obstacles facing the Saudi woman in the mixed environment. This is because of the spread of such phenomenon at mixed work environment that has been emphasized by many studies. Those studies have proved that about $(60 \%)$ of the American working women at military service and (61.4\%) of the Canadian working women have been exposed to harassment at mixed work environment. In general, many studies estimated that about $(40-60 \%)$ of the working woman at mixed environment were exposed, at least, to one kind of harassment (Faraj \& Haridi, 2004; Al-Shehri \& Al-Hindi, 2015; Mahan et al., 2008).

Professional obstacles were in the third place due to the interest of the woman in general and the Saudi woman in particular, in the social and ethical aspects in the first place. Saudi society is known by its commitment to the values, principles and ethics and their impact on the working woman. Whereas, psychological obstacles fell at the bottom of the obstacles list. Statistical analysis revealed that they were the least critical or important ones. That is, psychological obstacles affect only the working woman in the first place. The woman naturally can afford much of the psychological pressure and stress she faces at home or work.

\subsection{Discussion of the Results of the Second Question}

Results of the second question are seen logical where the traditions and customs of the tribal community are still having control on Najran in the southern part of Saudi Arabia. Furthermore, the social dimension is the dimension that worries the woman working in a mixed environment in Najran where many members within her community reject her admixture with men in the same place even though it is a public place. Unlike Najran, Riyadh is a civilized and open where the social obstacles, despite their importance for participants in the present study, do not represent the first obstacles dimension for the working woman. The ethical obstacles are really considered more important because of the harassment from the man's side due to the nature of somewhat open society.

With regard to the psychological and professional obstacles, there were no significant differences between the mean scores of both women in Najran and Riyadh. Problems of the same work and profession are somehow similar in all places, whether in Riyadh or Najran. Kanter (1997), for instance concluded that there were professional hindering the woman's professional and administrative progress in all jobs of the common nature 
despite the place of those jobs. Problems like the lack of equal opportunities with male counterparts and the lack of impact of the woman's experience and scientific qualification cause her to stay away from decision-making centers. Al-Subai'e (2010) and Al-Tarif (2014) claimed that there is much discrimination between men and women with regard to job promotions at mixed environments. The psychological problems that the working woman might face in the mixed environment are similar in all cities.

\subsection{Discussion of the Results of the Third Question}

Results of the second question are seen logical. Researchers such as Fitzgerald et al. (1999) and Faraj and Haridi (2004) refer such differences to the fact that the woman who works in the administrative fields admixes more with men because of the nature of her job to finish the transactions of both men and women. She also communicates more with her colleagues and bosses at work. The female physician or nurse, on the other hand, is in more contact with patients. The nature of their jobs makes them busy all the time leaving them less or no time to be in touch with men.

Results also revealed significant differences in the dimension of the psychological obstacles between women working in the field of nursing and women working in the administration area in favor of the latest. Ethical and psychological dimensions of the woman are the more psychological problems she has. Fitzgerald et al. (1999) and Faraj and Haridi (2004) showed that there are numerous psychological effects of harassment from which the working woman suffer such as anxiety, depression, low sense of good health, sleep and digestion disorder, and job dissatisfaction.

Results in Table 9 do not indicate any significant differences in the dimension of professional obstacles that can be due to the nature of the woman's job. All working women whether physicians, nurses, or managers suffer from the same professional problems and obstacles such as the control traditions and customs. That is, women remain under the control of men and will not at the centers of decision making despite the advanced scientific or professional ranks they achieve (Makhoul, 2006; Al-Tarif, 2014).

\subsection{Discussion of the Results of the Fourth Question}

Results related to the most effective proposals to overcome all kinds of obstacles facing the Saudi woman in the mixed work environment revealed that item (8) that stressed the importance of the application of instant penalties such as dismissing, moving away, or salary deduction when a male employee commits any kind of harassment was the most important. Participants in the present study believe that it is very important to issue legislations and laws that deter any kind of harassment towards the woman in the mixed work environment. In the second place were the items related to the solution of the professional obstacles because of the woman's sense of inequality regarding the matters of promotions, bonuses, and training workshops in comparison of her male colleagues. In short, this result is in agreement with the results of Al-Zahrani (2011), Al-Shehri and Al-Hindi (2015) and Mahan et al. (2008).

\section{Conclusion}

The present study aimed to identify the most important obstacles facing the Saudi woman in the mixed work environment. Analysis of collected data showed that there are many social, ethical, professional, psychological obstacles that can be as barriers for success in her work. Therefore, stakeholders and decision makers should do many things. They should separate the women's work environment from men's environment in all government and private institutions in line with Sharee'a teachings and just like some of the developed countries that began calling for the separation between genders, in order to provide a suitable environment for the woman's work to do her role freely without obstacles or barriers. They should also amend the current labor laws in the mixed work environment in line with the conditions and needs of the working woman and the culture of Saudi society. Furthermore, they should hold lectures and courses to help the working woman in the mixed work to understand the laws and regulations embedded in the labor law for her rights and duties. They should increase the awareness of the woman working in the mixed work environment about harassment phenomenon through holding periodic seminars awareness and the clarification of laws, regulations and policies relating to this matter. Instant penalties such as dismissing, moving away, or salary deduction in case of any complaint about any kind of harassment by any male employee should be applied. Certain laws and regulations that enable the woman to have her rights in promotion, rewards, bonuses, and training programs in the mixed work environment should be issued and modified. Media and cultural institutions, on the other hand, should do their role to aware the community of the importance of the woman's work and its role in the community growth and development. Media should also aware the working woman of her rights and duties in the mixed work environment.

Thus, the working woman will be encouraged to file a complaint to the specialized authorities when exposed to 
any kind of harassment while working. She can also.

\section{Ethics Statement}

All procedures performed in studies were review and approval by an ethics committee was not required for this study as per the institutional and national guidelines.

\section{Conflict of Interest Statement}

The authors declare that the research was conducted in the absence of any commercial or financial relationships that could be construed as a potential conflict of interest.

\section{Acknowledgements}

The research is funded by The Center for Promising Research in Social Studies and Women's Publications, Princess Nourah bint Abdulrahman University, Saudi Arabia, gratefully acknowledged.

\section{References}

Abdullah, A. A. (2012). Distant Work Center for Women Recruitment in Jeddah: A Study in Economic Geography. Kuwait Institution for Scientific Progress: Kuwait.

Adib, M., Al-Shatti, K., Kamal, S., El-Gerges, N., \&Al-Raqem, M. (2002). Violence against Nurses in Healthcare Facilities in Kuwait. International Journal of Nursing Studies, 93, 469-478. https://doi.org/10.1016/S0020-7489(01)00050-5

Al-Ashqar, W. M. (2013). Woman's work in light of the viewpoint of a sample of Jordanian university students. Journal of the Faculty of Education, Ain Shams University, 37(2), 135-155.

Al-Fawzan, M. B. (2012). The Work of Woman in Saudi Arabia. Bookshop of Law and Economy: Riyadh.

Al-Ja'afreh, S., \& Helmi, F. (2005). Workers' Mental Health in Certain Aspects of the Work Environment in the Jordanian Pharmaceutical Sector. Humanities and Social Sciences Studies, 32(2), 281-300.

Al-Johary, S. A. (2000). Factors Affecting the Attitudes of Saudi girl towards the Profession of Nursing (Unpublished MA thesis). King Abdul Aziz University, KSA.

Al-Juhani, M. (2000). Factors Affecting the Attitudes of Saudi Girl towards Work in the Health Sector (Unpublished MA Thesis). King Abdul Aziz University, KSA.

Al-Khamshi, S. S. (2014). Obstacles Facing Saudi Woman in Having Management Roles. Journal of Social Service, the Egyptian Association of Social Specialists, 52, 69-98.

Al-Shamlan, S. I. (2008). Saudi Woman and Work Regimes. Gulf Center for Research, 45, 44-45.

Al-Shammari, H. H. (2007). Obstacles Facing Saudi Woman and Hindering her Participation in Working at the Touristic Sector. Paper Presented to the Saudi Geographical Association 23rd meeting entitled" Tourism at Hail Region: Future Vision", 20-23rd/3/2007.

Al-Shammasi, A. A. (2001). The Number of Official Working Hours for the Working Woman and its Impact on her Productivity: A Field Study in some Governmental Departments in Jeddah (Unpublished MA thesis). King Abdul Aziz University, KSA.

Al-Shehri, N. A., \& Al-Hindi, W.A. (2015). Woman and Sexual Harassment at Work Environment: An Exploratory Study in the Banking Sector in Saudi Arabia. Journal of Arab Administrative Sciences, 22(3), 389-424.

Al-Subai'e, H. M. (2010). Social Problems Facing the Working Woman in the Mixed Work Environment (Unpublished MA thesis). School of Social Sciences, Imam Muhammad bin Saud Islamic University, KSA.

Al-Yousef, N. A. (2005). Participation of Saudi Woman in Labor Force: Reality and Challenges. Arab Economic Researches, 34, 149-180.

Al-Zahrani, S. K. (2011). Social Obstacles Facing the Working Woman in the Health Sector (Unpublished MA thesis). King Abdul Aziz University, KSA.

Al-Zamhari, S. (2009). Harmony between Saudi Women Privacy and her Participation in the Labor Market (Unpublished MA thesis). Naif Arab University for Security Sciences, Riyadh, KSA.

Al-Zoubi, R., \& Al-Kharouf, A. (2015). Youth Attitude toward the Woman's Work in the Tourism Sector: A Case Study of Students at the University of Jordan. Jordanian Journal of Social Sciences, 8(1), 67-107. https://doi.org/10.12816/0019994 
Argyle, M. (1993). The psychology of happiness (Translated by Feisal Abdul Kader Younis), Kuwait: National Council for Culture and Arts

Astrom, S., Bucht, G., Eisemann, M., Norberg, A., \& Saveman, B. (2002). Incidence of Violence towards Staff Caring for the Elderly. Scandinavian Journal of Caring Sciences, 16, 66-72. https://doi.org/10.1046/j.1471-6712.2002.00052.x

Commonwealth Secretariat. (1999). Gender Mainstreaming in the Public Service: A Reference Manual for Governments and Other Stakeholders. Retrieved October 22, 2009, from http://www.thecommonwealth.org/gender

Connell, R. (2006). The Experience of Gender Change in Public Sector Organizations Gender. Work \& Organization, 13(5), 435-452. https://doi.org/10.1111/j.1468-0432.2006.00316.x

Faisal, F. (2011). Impediments to Women's Equitable Employment: Global Scenario. Australian Journal of Business and Management Research, 1(3), 89-98.

Faraj, T. S., \& Huwaidi, A. M., (2004). Sexual Harassment of the Working Woman. Journal of the College of arts, Bani Suef University, 7, 1-48.

Fitzgerald, L, F., Drasgow, F., \& Masley, V. J. (1999). Sexual Harassment in the Armed Forces: A Test of the Integrated Model. Military Psychology, 11(3), 329-343. https://doi.org/10.1207/s15327876mp1103_7

Gerges, G. M. (2005). Glossary of Education Terms: Arabic-French-English (1st ed.). Beirut: Arab Renaissance Publishing House.

Ghaith, M. A. (2005). Dictionary of Sociology. Alexandria: Social Knowledge House.

Hasab Al-Nabi, M. (2013). Women in Labor: not by Harassment alone, Discrimination Occurs. Journal of Link, the Egyptian General Book Authority, 19, 16-19.

Howaishah, M. (2010). Jordanian Woman: Achievements, Challenges, Future Initiatives (2004-2009). National Committee for Woman's Affairs.

Ibrahim, A. S. (2013). A Proposal to Overcome the Obstacles Facing the Saudi Working Woman. Arab Studies in Education and Psychology, 39(4), 251-280.

International Labor Organization (ILO). (2004). Breaking through the Glass Ceiling: Women in Management. Retrieved September 12, 2009 from https://www.ilo.org/dyn/gender

Kabeer, N. (2003). Gender Mainstreaming in Poverty Eradication and the Millennium Development Goals. Canadian International Development Agency, Commonwealth Secretariat, International Development Research Centre. https://doi.org/10.14217/9781848598133-en

Kanter, P. (1997). Women of the corporation. New York: Basic book.

Lancaster, A. B., (1999). Department of Defense Sexual Harassment Research: Historical Perspectives and new Initiatives. Military Psychology, 11(3), 219-23. https://doi.org/10.1207/s15327876mp1103_1

Mahan, C., Stafford, J., Street, A., \& Hendricks, A. (2008). Sexual Harassment and Assault Experienced by Reservists during Military Service: Prevalence and health correlates. Journal of Rehabilitation research \& Development, 45(3), 409-420. https://doi.org/10.1682/JRRD.2007.06.0088

Makhoul, H. (2006). Unemployment and its Relationship with Crime in Saudi Arabia (Unpublished MA. thesis). Naif Academy for Secutrity Sciences, Riyadh, KSA.

Mitra, A. (2003) Establishment Size, Employment, and the Gender Wage Gap. Journal of Socio-Economics, 32(3), 317-330. https://doi.org/10.1016/S1053-5357(03)00042-8

Mrs. Khadija Bent Khuwaylid Center. (2013). Public Opinion Poll in Saudi Arabia about the Participation of Saudi Woman in the National Development. Chamber of Commerce and Industry in Jeddah, Saudi Arabia.

Nadia, F. (2012). Woman's Work and its Effect on Family Relations. Academy for Social and Humanistic Studies, $8,126-134$.

Najbah, M. (2014). Strategies of the Working Woman's Harmonization between her Family Roles and Outer Work. Journal of Hekma, 29, 126-140.

Oufi, M. (2003). The woman's Going out for Work and its Effect on Family Solidarity. Journal of Human Sciences, 19, 131-150.

Reuters. (2010). Indians Most Likely to Report Sexual Harassment at Work. Retrieved from 
http://in.reuters.com/article/idINIndia-50803120100812

Sa'ad, M. (2012). Violence against the Woman in the Workplace: Descriptive Study. Arabic studies in psychology, 11(2), 335-364.

Sepahi, A. (1997). Psychological Problems Related to Child Custody and Family Burdens of the Working Woman and their Effect on Her Productivity: Field Study at Clothing Laboratories of Syrian Ministry of Commerce (Unpublished Ph.D. Dissertation). College of Education, Damascus University.

Sharipova, M., Borg, V., \& Hogh, A. (2008). Prevalence, Seriousness and Reporting of Work-Related Violence in the Danish Elderly Care. Scandinavian Journal of Caring Sciences, 22, 574-581. https://doi.org/10.1111/j.1471-6712.2007.00577.x PMid:18801018

Viitasara, E., Sverke, M., \& Menckel, E. (2003). Multiple Risk Factors for Violence to Seven Occupational Groups in the Swedish Caring Sector. Industrial Relations, 58, 202-31. https://doi.org/10.7202/007302ar

Wei-Hsin, Y. (2005). Changes in Women's Post-marital Employment in Japan and Taiwan. Demography, 42(4), 693-717. https://doi.org/10.1353/dem.2005.0039

World Bank. (2001). Engendering Development through Gender Equality in Rights, Resources and Voice Policy Research Report. New York: Oxford University Press, Inc. Retrieved from http://siteresources.worldbank.org/PGLP/Resources/Engendering_Development.pdf

\section{Copyrights}

Copyright for this article is retained by the author(s), with first publication rights granted to the journal.

This is an open-access article distributed under the terms and conditions of the Creative Commons Attribution license (http://creativecommons.org/licenses/by/4.0/). 